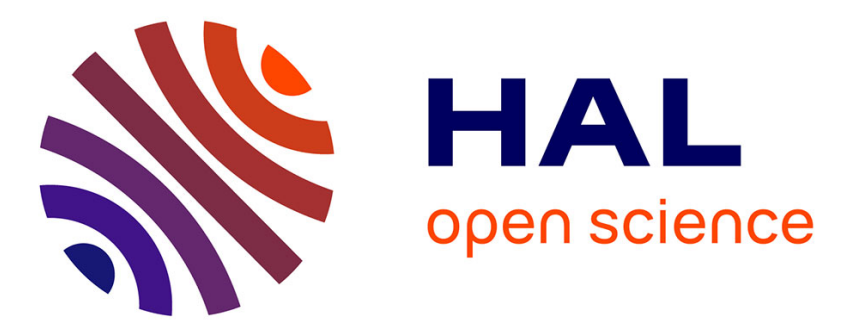

\title{
Simultaneous photoacoustic and luminescence multiple wavelength experiments
}

\author{
J. Tocho, M. Murphy, E. Rodríguez, F. Cussó
}

\section{To cite this version:}

J. Tocho, M. Murphy, E. Rodríguez, F. Cussó. Simultaneous photoacoustic and luminescence multiple wavelength experiments. Journal de Physique IV Proceedings, 1994, 04 (C7), pp.C7-405-C7-408. 10.1051/jp4:1994795 . jpa-00253326

\section{HAL Id: jpa-00253326 https://hal.science/jpa-00253326}

Submitted on 1 Jan 1994

HAL is a multi-disciplinary open access archive for the deposit and dissemination of scientific research documents, whether they are published or not. The documents may come from teaching and research institutions in France or abroad, or from public or private research centers.
L'archive ouverte pluridisciplinaire HAL, est destinée au dépôt et à la diffusion de documents scientifiques de niveau recherche, publiés ou non, émanant des établissements d'enseignement et de recherche français ou étrangers, des laboratoires publics ou privés. 


\title{
Simultaneous photoacoustic and luminescence multiple wavelength experiments
}

\author{
J.O. Tocho, M. Murphy*, E. Rodríguez** and F. Cussó** \\ Dto. de Física, Universidad Nacional de La Plata, and Centro de Investigaciones Opticas (CIC-CONIC), \\ Casilla de Correo 124, 1900 La Plata, Argentina \\ * Universidad Católica del Norte, Antofagasta, Chile \\ ** Dto. Física de Materiales C-IV, Universidad Autónoma de Madrid, 28049 Madrid, Spain
}

\begin{abstract}
Fluorescence quantum efficiencies in solid and liquid materials were determined by simultaneous photoacoustic and luminescence experiments after excitation at several wavelengths, with at least one of them connecting a relaxation of known quantum efficiency. Results for $\mathrm{Eu}^{2+}$ in alkaline halide, $\mathrm{Cr}^{3+}$ in $\mathrm{LiNbO}_{3}$, and a cyanine in ethanol solutions, are given.
\end{abstract}

\section{INTRODUCTION}

The fluorescence quantum efficiency $(\phi)$ of a luminescent material is obviously one of its most relevant parameters. Photoacoustic methods have been extensively used in the quantum efficiency determination of gases and liquid materials by comparing photoacoustic signals of the sample with that of a standard material with known quantum efficiency. ${ }^{1}$ For most solid state materials this procedure is not adequate because of the fact that changing the sample may affect the acoustic coupling.

An alternative method based on the simultaneous detection of photoacoustic and luminescent signals, after excitation at different wavelengths, was recently proposed. ${ }^{2}$ The comparison of the different photoacoustic (PAS) and luminescence (LUM) signals generated after excitation at two different wavelengths provides a method for absolute quantum efficiency determination.

\section{THEORY}

Fig. 1 represents a schematic energy diagram for materials used in this work. Different 
contributions to prompt heat and luminescence are indicated. The relaxation from the bottom of the lower excited state gives two thermal contributions: $q_{2}$ with efficiency $(1-\dot{\phi})$ and $q_{3}$ associated with the nonradiative relaxation within the ground state with efficiency $\phi$. A thermal contribution within excited state $\left(q_{1}\right)$ must be added. After excitation to a higher excited state.
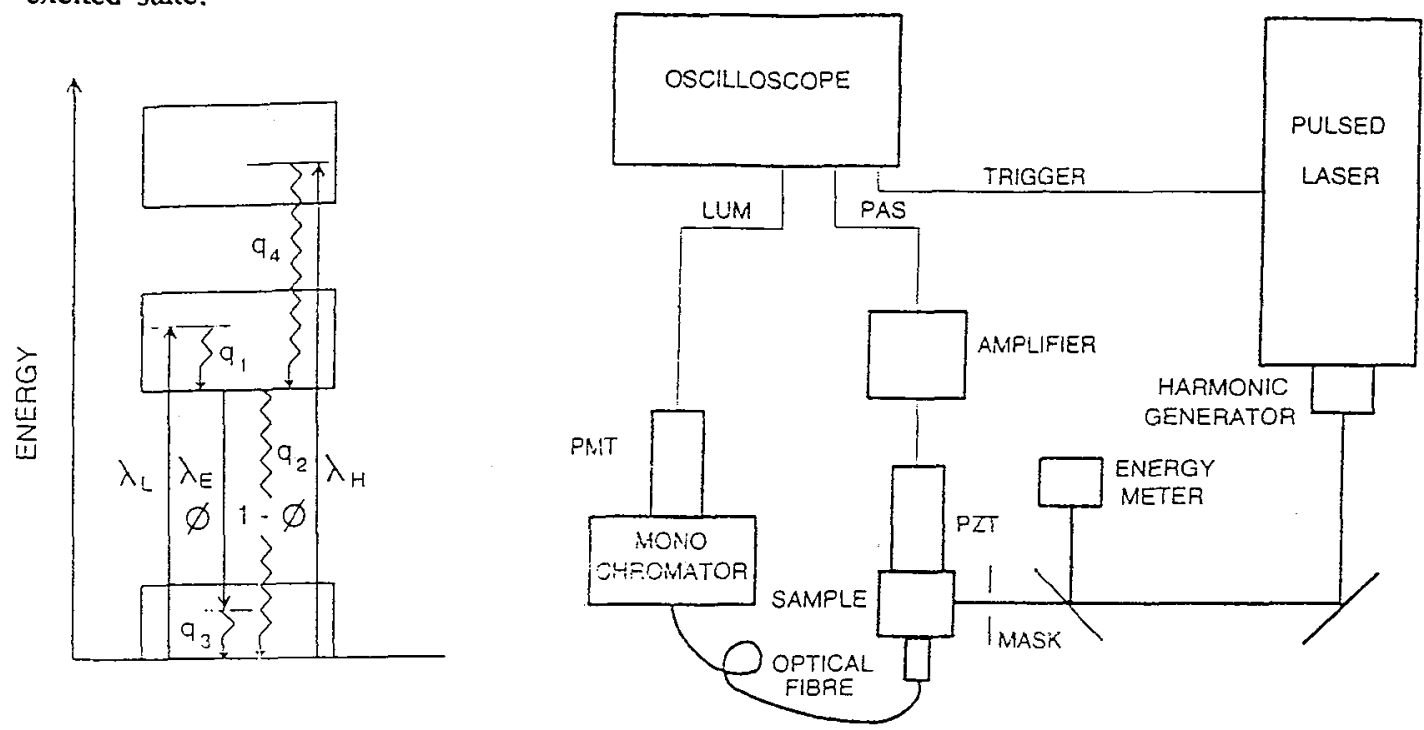

Fig. 1. Energy diagram indicating Fig. 2. Basic experimental setup different contributions to PAS used for simultaneous measurements and LUM. of PAS and LUM.

the nonradiative relaxation to the bottom of lower state produces a thermal contribution $q_{4}$ that must be added to the others. A fraction of this higher excited population might not be able to decay immediately to the lower states. This fraction will be designated with $\alpha$ and no contribution to prompt heat will be considered. Taken into account this loss, the photoacoustic and the luminescence signals after excitations with $\lambda_{L}$ or $\lambda_{H}$ photons can be written as:

$$
\begin{aligned}
& \operatorname{PAS}\left(\lambda_{L}\right)=K_{p}\left[q_{1}+(1-\phi) \cdot q_{2}+\phi \cdot q_{3}\right] \cdot N_{a}\left(\lambda_{L}\right), \\
& \operatorname{PAS}\left(\lambda_{H}\right)=K_{p} \cdot(1-\alpha) \cdot\left[q_{4}+(1-\phi) \cdot q_{2}+\phi \cdot q_{3}\right] \cdot N_{a}\left(\lambda_{H}\right), \\
& \operatorname{LUM}\left(\lambda_{L}\right)=K_{L} \cdot \phi \cdot N_{a}\left(\lambda_{L}\right), \\
& \operatorname{LUM}\left(\lambda_{H}\right)=K_{L} \cdot(1-\alpha) \cdot \phi \cdot N_{a}\left(\lambda_{H}\right),
\end{aligned}
$$

where $N_{a}\left(\lambda_{L}, \lambda_{H}\right)$ indicates the number of photons absorbed at each wavelength and $K_{P}$ and $K_{L}$ are 
instrumental constants for acoustic and luminescence detection. After some rearrangement of eq. [1-4], it can be demonstrated that the quantum efficiency is given by:

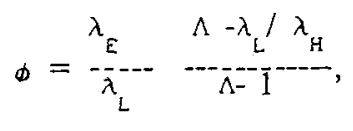

were $\lambda_{E}$ is the emission wavelength and $\Lambda$, which is the quantity to be experimentally determined, is given by the ratio between of slopes of the photoacoustic (PAS) signal in terms of the amount of detected luminescence (LUM) signal excited at different flux densities of high $\left(\lambda_{H}\right)$ or low $\left(\lambda_{L}\right)$ energies:

$$
\Lambda=\frac{\partial \operatorname{PAS}\left(\lambda_{H}\right) / \partial \operatorname{LUM}\left(\lambda_{H}\right)}{\partial \operatorname{PAS}\left(\lambda_{L}\right) / \partial \operatorname{LUM}\left(\lambda_{L}\right)}
$$

\section{EXPERIMENTAL}

The method described above is applied in the present work to different materials, $\mathrm{Eu}^{+2}$ ions in $\mathrm{KCl}, \mathrm{Cr}^{-3}$ in ferroelectric $\mathrm{LiNhO}_{3}$, and to a well known liquid material as it is a solution of dimethyloxidicarbocyanine iodide (DODCl). Photoacoustic and luminescent signals were simultaneously detected by using a resonant PZT, and a photomultiplier-monochromator combination. Solid samples were cut in the form of rectangular slabs of $10 \times 5 \times 1 \mathrm{~mm}$. Liquid samples were contained in $10 \times 10 \times 40 \mathrm{~mm}$ quartz cells. Fluorescence was collected with an optical fiber in both cases. Pump flux was changed with a variable density wedge (visible) or a half wave - polarizer combination (UV).

Absorption bands of $\mathrm{Eu}^{+2}$ ions in alkali halide crystals were excited with the third and fourth harmonics of Nd:YAG laser at $\lambda=355 \mathrm{~nm}$ and $\lambda=266 \mathrm{~nm}$ respectively. Two wavelengths (500 nm and $660 \mathrm{~nm}$ ) of a nitrogen pumped dye-laser were used to excite the absorption bands of $\mathrm{Cr}^{+3}$ in $\mathrm{LiNbO}_{3}$. The fundamental wavelength $(\lambda=600 \mathrm{~nm})$ and second harmonic $(\lambda=300 \mathrm{~nm})$ of a flash lamp pumped dye-laser (Rh 6G) were used to measure a solution of DODCl in ethanol. The experimental set-up can be seen in Fig. 2.

\section{RESULTS AND DISCUSSION}

From the results shown in figures 3 for solid materials, fluorescence quantum yields were calculated as: $\Phi(\mathrm{Eu}: \mathrm{KCl})=1.04 \pm 0.06, \Phi(\mathrm{Cr}: \mathrm{LiNbO3})=0.05 \pm 0.02$. For the liquid sample, a prior experiment was performed in order to check the validity of the model described by eq. [14]. Luminescence excited by $295 \mathrm{~nm}$ and by $590 \mathrm{~nm}$ was plotted in terms of exciting energy. A factor of 2 relating the two slopes of Fig. 4 contirmed that almost all molecules excited to 
the high energy level relax through the radiative state $S_{1}$. From Fig. 3 and by using eq. 5 , $\phi(D O D C l)$ can be calculated as $0.52 \pm 0.06$. As is well known, the phorophysics of DODCI is more complicated and isomerization channels starting at $S_{1}$ can accumulate energy in the metastable species. ${ }^{3}$ This fact will slightly reduce the value calculated for $\phi$.

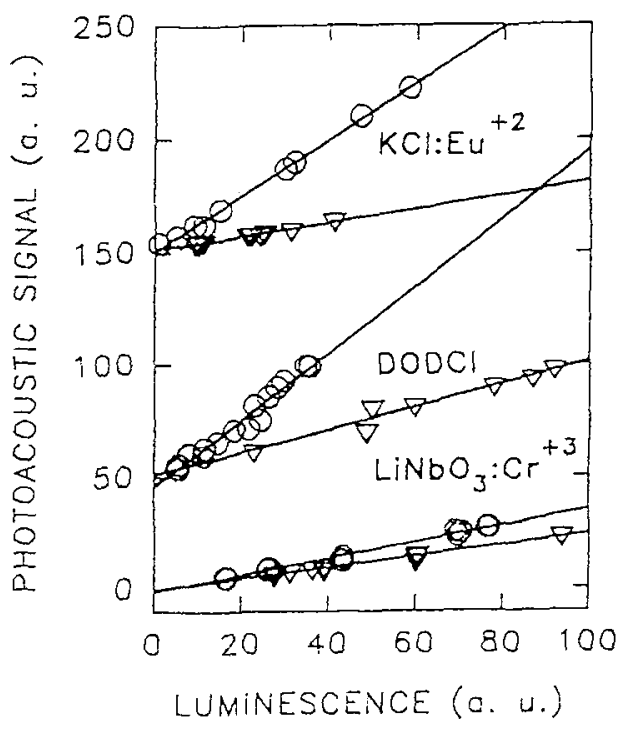

Fig. 3. Experimental results from which $\Lambda$ and $\phi$ can be calculated.

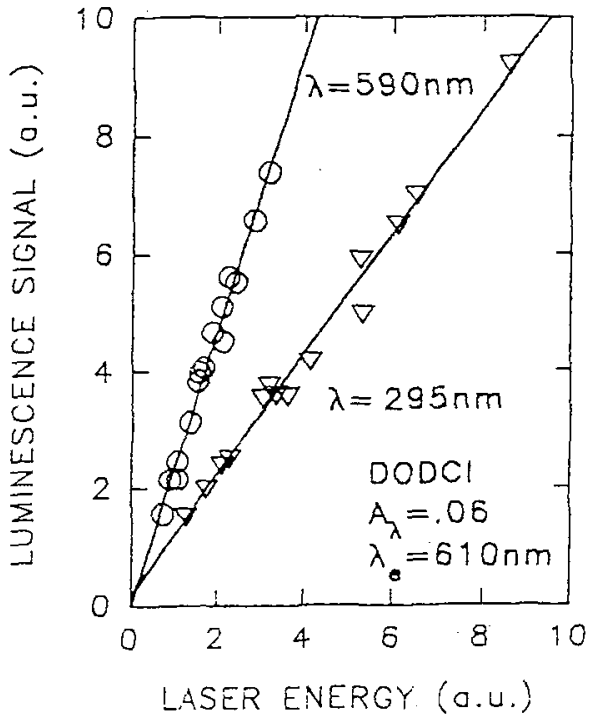

Fig. 4. Luminescence intensity for DODCI excited at two wavelengths.

\section{REFERENCES}

[1] S.E. Braslavsky and K. Heihoff, Handbook of Organic Photochemistry, ed. J.C. Scaino, CRC, Boca Ratón, 1989.

[2] E. Rodríguez, J.O. Tocho and F. Cussó, Phys. Rev. B47, (1993) 14049.

[3] R. Duchowicz, L. Scaftardi and J.O. Tocho, Chem. Phys. Lett. 170, (1990) 497. 